\title{
Frontières
}

\section{CHÂTELET, Noëlle, La Dernière Leçon, Paris, Éditions du Seuil, 2004, 170 p.}

\section{Shahira El Moutei-Khalil}

Volume 18, numéro 2, printemps 2006

URI : https://id.erudit.org/iderudit/1073233ar

DOI : https://doi.org/10.7202/1073233ar

Aller au sommaire du numéro

Éditeur(s)

Université du Québec à Montréal

ISSN

1180-3479 (imprimé)

1916-0976 (numérique)

Découvrir la revue

Citer ce compte rendu

El Moutei-Khalil, S. (2006). Compte rendu de [CHÂTELET, Noëlle, La Dernière Leçon, Paris, Éditions du Seuil, 2004, 170 p.] Frontières, 18(2), 80-80.

https://doi.org/10.7202/1073233ar

Ce document est protégé par la loi sur le droit d'auteur. L'utilisation des services d'Érudit (y compris la reproduction) est assujettie à sa politique d'utilisation que vous pouvez consulter en ligne.

https://apropos.erudit.org/fr/usagers/politique-dutilisation/
Cet article est diffusé et préservé par Érudit.

Érudit est un consortium interuniversitaire sans but lucratif composé de l’Université de Montréal, l'Université Laval et l'Université du Québec à Montréal. Il a pour mission la promotion et la valorisation de la recherche. https://www.erudit.org/fr/ 


\section{CHÂTELET, Noëlle La Dernière Leçon}

Paris, Éditions du Seuil 2004, $170 \mathrm{p}$.

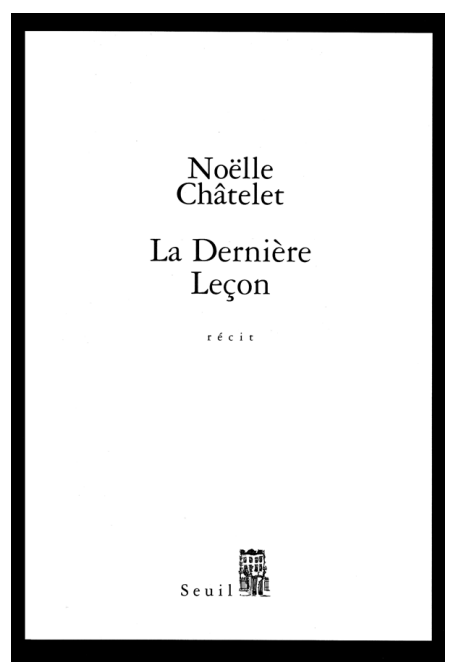

Dans son livre, Noëlle Châtelet nous raconte comment sa mère, Mireille Jospin, âgée de 92 ans, a décidé de programmer sa mort avant la "déglingue" physique et morale. Mireille Jospin demande à ses enfants de la soutenir dans son geste et de lui donner du courage. Elle, de son côté, les aidera, et notamment Noëlle, à entreprendre un travail de deuil, que l'on fait habituellement après la mort d'un être cher.

Il faut dire qu'au début, on ne comprend pas trop pourquoi madame Jospin se presse de fixer la date de sa mort, puisqu'elle n'est pas malade ni réellement diminuée. Est-ce par souci de dignité pour épargner aux siens le spectacle de sa déchéance, est-ce par besoin de contrôler la dernière étape de sa vie? Pourquoi ce besoin de tout préparer et organiser? Par la suite, on apprend que Mireille Jospin a milité activement au sein de l'Association pour le droit de mourir dans la dignité, et l'on comprend mieux sa décision.

Mais le pourquoi de cette décision ainsi que la définition de l'indignité et les critères qui la déterminent ne sont pas l'objet de ce récit. En fait, Noëlle Châtelet $s$ 'adresse à sa mère pour lui dire ce qu'elle a éprouvé durant les derniers mois qui ont précédé cette mort annoncée, et lui avouer, aprèscoup, tout ce qu'elle ne lui avait pas dit: ses doutes, ses terreurs, ses angoisses et sa tristesse.

Lorsque la mère annonce à ses enfants la date fatidique, Noëlle Châtelet est complètement désemparée, elle comprend qu'elle n'était pas du tout prête à entendre cette "phrase guillotine» qui a pour effet de lui glacer le sang, de l'anesthésier, de lui donner l'impression que la vie se retirait d'elle et qu'elle ne pouvait plus rien ressentir d'autre que le froid de la mort. Face à ce compte à rebours, elle se rebiffe et proteste, éprouve de la colère, de la peur, de l'angoisse, alors qu'elle se croyait prête, elle qui avait promis d'être au rendez-vous et de vivre ce moment avec sa mère.

Au fil de la lecture, on s'attache énormément au personnage de la mère qu'on découvre: sage-femme elle a toute sa vie aidé à donner la vie; à quatre-vingt-six ans, elle part au Mali, au fond de la brousse, pour pratiquer son métier de sage-femme! Elle est généreuse, courageuse, volontaire et rien ne lui fait perdre son sens de I'humour. Sa relation avec sa fille est extraordinaire: riche et intense, empreinte d'amour et de confiance, une relation qui privilégie le respect et le dialogue. Cette femme impressionnante va poursuivre son rôle de mère jusqu'au bout, puisqu'elle va aider sa fille à apprivoiser la mort, la lui enseigner en quelque sorte, comme elle lui avait enseigné la vie, avec amour, humour et patience. C'est en ces termes que Noëlle Châtelet décrit à sa mère le rôle qu'elle a joué dans cet apprentissage: «[...] je retrouvais dans la manière dont tu guidais mes pas inquiets et hésitants quelque chose d'incroyablement tendre, familier. II me semblait te revoir, tout aussi attentive, m'aidant à tenir ma fourchette ou ma plume pour mes lignes de $o$ et de $a$. Tu m'apprenais ta mort comme tu $\mathrm{m}$ 'avais appris à manger et à écrire, me corrigeant, me reprenant, prête à voler à mon secours, prompte à me soutenir.»

Afin d'aider sa fille dans son travail de deuil, madame Jospin ne va pas ménager ses efforts pour banaliser sa mort et vivre en sa présence des petits deuils symboliques qui annoncent la séparation. Elle va, par exemple, ranger des photos, des souvenirs, des objets, faire des dons d'objets ou encore inscrire sur les objets leur origine ou le nom de leur destinataire. En fait, elle ne se contente pas de mettre de l'ordre, elle fait un travail de deuil, puisqu'elle déterre des souvenirs, revoit en imagination, une dernière fois, les choses du passé, le chemin parcouru, relie les objets et les souvenirs à sa vie avant de leur dire adieu.

Madame Jospin accomplit tous ces gestes ostensiblement devant sa fille pour l'amener à commencer son travail de deuil. D'ailleurs, Noëlle a bien compris ce que les gestes de sa mère représentent puisqu'elle lui dit: "Mais ce que je retrouvais, à travers ce désir farouche de ritualiser ta mort et que j'avais déjà entrevu à travers la danse des objets et la chorégraphie du don, c'est ta volonté forcenée d'inverser la symbolique du deuil: tu voulais vivre avant les gestes de l'après. Tu souhaitais, le plus possible, accomplir avec nous le temps du deuil, le temps de la mort."

Bien que Noëlle ait douté de ce travail d'apprivoisement de la mort, elle convient de son erreur: "Je ne t'ai pas dit combien je doutais alors de l'efficacité de ton vaccin [...] Je n'y ai jamais tout à fait cru, à cette homéopathie de l'âme. J'avais tort. » De plus, Noëlle croyait ne jamais revenir du froid de la mort qu'elle a ressenti lorsque sa mère a annoncé la date fatidique. Et pourtant, grâce au travail de deuil effectué avec l'aide de sa mère, de sa présence tendre et attentive, de son soutien constant, Noëlle Châtelet avoue d'emblée au début de son récit: "J'avais tort: je suis chaude à présent. Chaude et vivante."

En fait, Noëlle Châtelet est tellement impressionnée par le chemin que sa mère lui a fait parcourir dans le travail de deuil, qu'elle voudrait mettre l'expérience en mots pour que d'autres en bénéficient. Elle estime que ce récit servirait le combat que sa mère avait mené auprès de l'Association pour le droit à mourir dans la dignité et aiderait les personnes qui tenteraient d'apprivoiser la mort ou de la regarder autrement. Lorsqu'elle demande à sa mère son consentement, celle-ci s'interroge dans un premier temps sur l'utilité d'un tel livre pour ensuite l'encourager à l'écrire: "Raconte. Oui, écris-le. Je te fais confiance."

Un très beau livre, magnifiquement écrit, rempli d'amour et de tendresse, qui offre matière à réflexion et qui pourrait aider certaines personnes qui le liraient. On aurait toutefois aimé que la mère nous parle de ses propres angoisses, de ses réactions face à cette mort choisie, qu'elle nous dise comment elle vivait cette dernière étape, ce compte à rebours dont elle avait elle-même fixé l'échéance sans y être obligée.

Shahira El Mouthei-Khalil 